\title{
Helicobacter pylori infection status had no influence on upper gastrointestinal symptoms: a cross-sectional analysis of 3,005 Japanese subjects without upper gastrointestinal lesions undergoing medical health checkups
}

\author{
Tomomi Yoshioka $^{1,2} \cdot$ Eri Takeshita $^{1,2,4} \cdot$ Yasuhisa Sakata $^{1,2} \cdot$ Megumi Hara $^{3} \cdot$ Kayo Akutagawa $^{1,2} \cdot$ Natsuko Sakata $^{4}$. \\ Hiroyoshi Endo $^{5}$ - Takashi Ohyama ${ }^{6}$ Keiji Matsunaga ${ }^{4}$ Yuichiro Tanaka ${ }^{1,2}$ - Shinpei Shirai ${ }^{1,2,5} \cdot$ Yoichiro Ito $^{1,2}$ • \\ Nanae Tsuruoka ${ }^{1,2} \cdot$ Ryuichi Iwakiri $^{1,2} \cdot$ Motoyasu Kusano $^{7} \cdot$ Kazuma Fujimoto $^{1,2,6}$
}

Received: 26 October 2016 / Accepted: 1 March 2017 / Published online: 15 March 2017

(c) The Author(s) 2017. This article is published with open access at Springerlink.com

\begin{abstract}
Background This study aimed to evaluate the influence of Helicobacter pylori infection and its eradication on the upper gastrointestinal symptoms of relatively healthy Japanese subjects.

Methods A total of 3,005 subjects (male/female: $1,549 / 1,456)$ undergoing medical health checkups were enrolled in the present study, at five hospitals in Saga, Japan, from January to December 2013. They had no significant findings following upper gastrointestinal endoscopy. All subjects completed a questionnaire that addressed a frequency scale for symptoms of gastroesophageal reflux disease. The questionnaire comprised seven questions regarding reflux symptoms and seven regarding acidrelated dyspepsia, which were answered with a score based on the frequency of symptoms. Helicobacter pylori infection was identified by a rapid urease test and/or $H$. pylori antibody titer, and an eradication history was confirmed by the subjects' medical records.
\end{abstract}

Kazuma Fujimoto

fujimotk@cc.saga-u.ac.jp

1 Department of Internal Medicine, Saga Medical School, 5-1-1 Nabeshima, Saga 849-8501, Japan

2 Department of Gastrointestinal Endoscopy, Saga Medical School, Saga, Japan

3 Department of Preventive Medicine, Saga Medical School, Saga, Japan

4 Yuaikai Oda Hospital, Kashima, Saga, Japan

5 Saiseikai Karatsu Hospital, Karatsu, Saga, Japan

6 Takagi Hospital, Okawa, Fukuoka, Japan

7 Department of Endoscopic Surgery, Gunma University Hospital, Maebashi, Japan
Results Helicobacter pylori infection was positive in 894 subjects out of 3,005 (29.8\%). Eradication of Helicobacter pylori was successfully achieved in 440 subjects of 458 treated. Helicobacter pylori infection had no influence on the acid-related dyspepsia evaluated by the questionnaire, whereas the mean reflux score was relatively high in the Helicobacter pylori native negative subjects compared to Helicobacter pylori native positive. Eradication of Helicobacter pylori and time span after the eradication had no effect on the upper gastrointestinal symptoms evaluated by the questionnaire.

Conclusion Helicobacter pylori infection and history of eradication did not affect acid-related dyspepsia symptoms in Japanese healthy subjects.

Keywords Reflux esophagitis · Gastroesophageal reflux disease (GERD) · Reflux symptoms · Functional dyspepsia $\cdot$ Frequency scale for the symptoms of GERD (FSSG)

\section{Introduction}

An annual survey on public health conducted by the Ministry of Health, Labour and Welfare of Japan in 2013 indicated that $27.68 \%$ of males and $31.24 \%$ of females had some clinical symptoms regarding the gastrointestinal tract [1]. Several studies in Western countries indicated a relationship between Helicobacter pylori infection and clinical symptoms of the upper gastrointestinal tract, while the beneficial effect of $H$. pylori eradication on these symptoms was complex [2-4]. Improvement of upper gastrointestinal tract symptoms after $H$. pylori eradication is still unclear in Japan [5-12], although several prospective randomized studies in Asia and South America showed the efficacy of 
eradication therapy $[13,14]$. These reports indicate that a relationship between dyspepsia symptoms and $H$. pylori infection is still controversial.

Although previous studies indicated that reflux esophagitis was developed following eradication therapy [4, 15], recent studies in Japan have indicated that the frequency or severity of this esophagitis, evaluated by endoscopy, was not serious [16-20]. Evaluation of reflux symptoms after eradication can be difficult, and one study in Japan suggested that the reflux symptoms might be improved and/or not exacerbated after eradication [21].

The aims of the present cross-sectional study were to determine: (1) whether reflux symptoms and acid-related dyspepsia were different between $H$. pylori positive and negative subjects; and (2) whether these symptoms were influenced by eradication of $H$. pylori. Using the modified frequency scale for symptoms of gastroesophageal reflux disease (FSSG) questionnaire [22, 23], upper gastrointestinal symptoms were evaluated in relatively healthy subjects presenting for medical health checkups, with no lesion revealed by upper gastrointestinal endoscopy.

\section{Patients and methods}

A total of 3,505 subjects (male/female: 1,922/1,583) received upper gastrointestinal endoscopy during medical health checkups at five hospitals in Saga, Japan, from January to December 2013, as described in a previous study [24]. Written informed consent was obtained from all subjects. Among the subjects, 500 were excluded from the present analysis: 395 subjects with endoscopic reflux esophagitis (graded according to the Los Angeles classification [25]; 27 with gastric cancer and/or gastric ulcers; 24 with duodenal ulcers; and 54 who were prescribed with anti-acid medicines (histamine- 2 receptor antagonists or proton pump inhibitors), and/or prokinetics. Thus, 3,005 subjects were enrolled in the present analysis, all with no lesions which could lead to upper gastrointestinal symptoms. H. pylori infection was identified by a rapid urease test and/or $H$. pylori antibody titer, and an eradication history was confirmed by the subject's medical record and medical history form to confirm the time span after eradication. The successfully eradicated subjects were divided into two groups: the time span was more than 3 years and less than 3 years.

All subjects completed a modified FSSG questionnaire, which is a self-administered, validated questionnaire comprising 14 questions, with seven regarding reflux symptoms and seven regarding acid-related dyspepsia [22]. Each symptom is assigned a score [never experienced $=0$; occasionally ( $30 \%$ of the time) $=1$; sometimes $(50 \%)=2$; often $(70 \%)=3$; and always $(100 \%)=4]$. The seven questions about reflux symptoms are: Q1, "Do you get heartburn?"; Q2, "Do you sometimes subconsciously rub your chest with your hand?"; Q3, "Do you get heartburn after meals?"; Q4, "Do you have an unusual (e.g. burning) sensation in your throat?"; Q5, "Do some things get stuck when you swallow?"; Q6, "Do you feel a bitter liquid (acid) coming up into your throat?"; and Q7, "Do you get heartburn if you bend over?". The seven questions about acid-related dyspepsia are: Q8, "Does your stomach get bloated?"; Q9, "Does your stomach ever feel heavy after meals?"; Q10, "Do you feel sick after meals?"; Q11, "Do you feel full while eating meals?"; Q12, "Do you burp a lot?"; Q13, "Do you feel pain in the upper abdomen after meals?"; Q14, "Do you feel pain in the upper abdomen while fasting?".

All procedures performed in this study were approved by the Ethical Committee of Saga University Hospital (2014-09-15). Statistical evaluation was carried out using the $\chi^{2}$ test and Welch's $t$ test (using SPSS software, version 22; SPSS, Tokyo, Japan), and statistical significance was established at a $p$ value of $<0.05$.

\section{Results}

Table 1 shows the background characteristics of all 3,005 subjects enrolled in the present study. Their average age was $\mathbf{5 4 . 2}$ years, and the numbers of male and female subjects were almost equal. The comorbidity rate of hiatus herniation was $29.6 \%(894 / 3,005)$. The rate of short segment Barrett's esophagus was relatively high (23.7\%), whereas the rate of long segment Barrett's esophagus was very low $(0.3 \%)$. Gastric ulcer scars and duodenal ulcer scars were detected by endoscopy only in 3.0 and $2.6 \%$ of subjects, respectively. The rate of $H$. pylori infection was $29.8 \%$ (894/3,005: native positive) at the time of the subjects' medical health checkups. A total of 458 subjects

Table 1 Characteristics of Japanese subjects presenting for medical checkups $(n=3,005)$ evaluated by upper gastrointestinal endoscopy

\begin{tabular}{ll}
\hline Age (years) & $54.2 \pm 9.1$ \\
Gender (males: females) & $1,549: 1,456$ \\
Body mass index $\left(\mathrm{kg} / \mathrm{m}^{2}\right)^{\mathrm{a}}$ & $22.8 \pm 5.2$ \\
Number with $H$. pylori infection & $894(29.8 \%)$ \\
Number with successful eradication of H. pylori & $440(14.6 \%)$ \\
Number with hiatus herniation & $888(29.6 \%)$ \\
Number with Barrett's esophagus & \\
Short segment & $712(23.7 \%)$ \\
Long segment & $10(0.3 \%)$ \\
Number with gastric ulcer scars & $91(3.0 \%)$ \\
Number with duodenal ulcer scars & $77(2.6 \%)$ \\
\hline
\end{tabular}

a Mean \pm SD 
had a history of $H$. pylori eradication therapy. The infection had been successfully eradicated in 440 subjects (14.6\%: eradicated negative). As shown in Table 2, the eradication therapy had failed in 18 subjects (eradicated positive), giving an eradication rate of $96.1 \%$ (440/458).

Table 3 shows the FSSG scores for reflux symptoms and acid-related dyspepsia compared between $H$. pylori positive and negative subjects. The symptoms evaluated by the FSSG were compared between two groups: an $H$. pylori native negative group versus an $H$. pylori native positive group. Age and body mass index (BMI) were not different between the groups, and other subject-related characteristics were not different between the groups. The score for acid-related dyspepsia was not different between the $H$. pylori native negative and positive groups, indicating that $H$. pylori infection had no influence on dyspepsia symptoms in subjects presenting for medical checkups. In contrast, the mean score for reflux symptoms evaluated by the FSSG was significantly higher in the $H$. pylori native negative group compared with the native positive group $(p<0.05)$. However, greater response with score reduction 2 or more for each question regarding reflux symptoms (Q1-Q7) were not different between $H$. pylori native negative and positive groups (data not shown).

Reflux symptoms and acid-related dyspepsia were also compared between the two groups: subjects for whom $H$.

Table 2 Helicobacter pylori infection and eradication therapy (numbers of subjects)

\begin{tabular}{lll}
\hline & $\begin{array}{l}\text { History of eradication } \\
\text { therapy }\end{array}$ & No eradication therapy \\
\hline $\begin{array}{l}\text { H. pylori positive } \\
\text { H. pylori negative }\end{array}$ & $\begin{array}{l}440 \text { (eradicated positive) } \\
\text { tive) }\end{array}$ & 876 (native positive) \\
& 1,671 (native negative) \\
\hline
\end{tabular}

pylori eradication was successful (eradicated negative) versus subjects who were infected with $H$. pylori and never received eradication therapy (native negative). As indicated in Table 3 (the lower low), age and BMI were not different between the two groups. The acid-related dyspepsia score for the successful eradication subjects (eradicated negative) was not better compared with that for the $H$. pylori positive subjects (native positive). Reflux symptoms in the successful eradication subjects (eradicated negative) were not exacerbated compared with $H$. pylori positive subjects (native positive), as the reflux symptoms scores were almost the same in these two groups.

Table 4 shows the effect of the time span after eradication therapy for $H$. pylori. The time span was not detected for 52 out of 440 eradicated subjects. As shown, neither the score for reflux symptoms nor the score for acid-related dyspepsia depended on the time span after eradication, whereas we did not follow up the same subjects as the present report was a cross-sectional study.

\section{Discussion}

The present study indicated that $H$. pylori infection had no influence on acid-related dyspepsia in relatively healthy Japanese subjects presenting for medical checkups. $H$. pylori infection is a major cause of peptic ulcers and gastric cancer, but this study excluded these diseases using upper gastrointestinal endoscopy. The subjects in the present study had fewer clinical symptoms compared with patients who visit a hospital, which might be one of the reasons there were no differences in dyspepsia between $H$. pylori positive and negative subjects as most of $H$. pylori related dyspeptic patients defined by Roma IV criteria [26] was excluded from the present study. Moreover, most previous

Table 3 Comparison of total scores from FSSG questionnaire for reflux symptoms and acid-related dyspepsia, between Helicobacter pylori negative and positive subjects

\begin{tabular}{llll}
\hline & H. pylori native negative $(n=1,671)$ & H. pylori native positive $(n=876)$ & $p$ value \\
\hline Acid-related dyspepsia $^{\mathrm{a}}$ & $1.69 \pm 2.67$ & $1.64 \pm 2.37$ & 0.62 \\
Reflux symptoms $^{\mathrm{a}}$ & $2.10 \pm 2.87$ & $1.85 \pm 2.59$ & 0.03 \\
${\text { Age }(\mathrm{year})^{\mathrm{a}}}^{\mathrm{B}}$ & $54.3 \pm 7.9$ & $54.0 \pm 9.3$ & 0.22 \\
${\text { BMI }\left(\mathrm{kg} / \mathrm{m}^{2}\right)^{\mathrm{a}}}$ & $22.9 \pm 6.2$ & $22.8 \pm 3.3$ & 0.61 \\
\hline Acid-related dyspepsia $^{\mathrm{a}}$ & Eradicated negative $(n=440)$ & H. pylori native positive $(n=876)$ & 0.96 \\
Reflux symptoms $^{\mathrm{a}}$ & $1.63 \pm 2.38$ & $1.64 \pm 2.37$ & 0.60 \\
Age $^{\mathrm{a}}$ & $1.78 \pm 2.45$ & $1.85 \pm 2.59$ & 0.48 \\
BMI $^{\mathrm{a}}$ & $54.4 \pm 7.8$ & $54.0 \pm 9.3$ & 0.13 \\
\hline
\end{tabular}

FSSG frequency scale for the symptoms of gastroesophageal reflux disease, $B M I$ body mass index

${ }^{\text {a }}$ Mean \pm SD 
Table 4 Effects of the time span after eradication on FSSG scores

\begin{tabular}{llll}
\hline & Less than 3 years after eradication $(n=128)$ & More than 3 years $(n=260)$ & $p$ value \\
\hline Acid-related dyspepsia $^{\mathrm{a}}$ & $1.57 \pm 2.08$ & $1.81 \pm 2.58$ & 0.10 \\
Reflux symptoms $^{\mathrm{a}}$ & $1.70 \pm 2.53$ & $1.78 \pm 2.40$ & 0.76 \\
Age $^{\mathrm{a}}$ & $54.0 \pm 8.2$ & $54.3 \pm 7.8$ & 0.71 \\
BMI $^{\mathrm{a}}$ & $22.9 \pm 3.2$ & $23.0 \pm 3.8$ & 0.83 \\
\hline
\end{tabular}

FSSG frequency scale for the symptoms of gastroesophageal reflux disease, BMI body mass index

a Mean \pm SD

Japanese studies have similarly suggested that there is no relationship between upper gastrointestinal symptoms (dyspepsia) and $H$. pylori infection [5-12].

The total score for reflux symptoms was higher in the $H$. pylori negative group compared with the $H$. pylori positive group. Whereas subjects with Los Angles classification grade A-D reflux esophagitis were not included in the present study, those subjects with grade $\mathrm{M}$ or $\mathrm{N}[12,27$, 28 ] were included. This might be a cause of higher scores for reflux symptoms. It is also possible that reflux symptoms might be more common in relatively healthy $H$. pylori negative subjects compared with similar $H$. pylori positive subjects in Japan.

Eradication of $H$. pylori had no influence on upper gastrointestinal symptoms in the present study. Regarding this eradication, the data were evaluated retrospectively, and the eradication itself and the time span after eradication changed neither the reflux nor the dyspepsia scores from the modified FSSG questionnaire. Previous studies indicated that endoscopic reflux esophagitis was developed after eradication [4, 15-20]. This study excluded endoscopic reflux esophagitis, and the upper gastrointestinal symptoms assessed by the FSSG were not affected by $H$. pylori eradication in subjects without reflux esophagitis. Previous reviews suggested that the time span after eradication might be important for the clinical symptoms [16, $18,27]$. Namely, reflux symptoms appeared after the eradication might be diminished in a time dependent manner after the eradication. The present study indicated the time span after eradication had no effect on the score of FSSG whereas this cross-sectional study did not follow up the same subjects.

In summary, the present study indicated that $H$. pylori infection did not affect upper gastrointestinal symptoms in relative healthy Japanese subjects presenting for medical checkups with no significant upper gastrointestinal lesions.

\section{Compliance with ethical standards}

Ethical Statement All procedures followed were in accordance with the ethical standards of the responsible committee on human experi- mentation (institutional and national) and with the Helsinki Declaration of 1964 and later versions. Informed consent or substitute for it was obtained from all patients for being included in the study.

\section{Conflict of interest None.}

Open Access This article is distributed under the terms of the Creative Commons Attribution 4.0 International License (http://creativecommons.org/licenses/by/4.0/), which permits unrestricted use, distribution, and reproduction in any medium, provided you give appropriate credit to the original author(s) and the source, provide a link to the Creative Commons license, and indicate if changes were made.

\section{References}

1. Journal of Health and Welfare Statistics (Japan) 2014/2015; p. 87-89.

2. Talley NJ, Ford AC. Functional dyspepsia. N Engl J Med. 2015;373:1853-63.

3. Lundell L, Vieth M, Gibson F, Nagy P, Kahrilas PJ. The effect of long-term proton pump inhibitor use on serum gastrin levels and gastric histology. Aliment Pharmacol Ther. 2015;42:649-63.

4. Malfertheiner P, Megraud F, O'Morain CA, Atherton J, Axon AT, Bazzoli F, Gensini GF, Gisbert JP, Graham DY, Rokkas T, El-Omar EM, Kuipers EJ, European Helicobacter Study Group. Management of Helicobacter pylori infection-the Maastricht IV/Florence consensus report. Gut. 2012;61:646-64.

5. Suzuki H, Moayyedi P. Helicobacter pylori infection in functional dyspepsia. Nat Rev Gastroenterol Hepatol. 2013;10:168-74.

6. Miwa H. Why dyspepsia can occur without organic disease: pathogenesis and management of functional dyspepsia. J Gastroenterol. 2012;47:862-71.

7. Manabe N, Haruma K. Diagnosis and treatment of dyspeptic patients in Japan. J Gastroenterol Hepatol. 2011;26(Suppl 3):27-31.

8. Furuta T, Delchier JC. Helicobacter pylori and non-malignant diseases. Helicobacter. 2009;14(Suppl 1):29-35.

9. Azuma T, Ito Y, Suto H, Ohtani M, Dojo M, Muramatsu A, Kuriyama M, Kato T. The effect of Helicobacter pylori eradication therapy on dyspepsia symptoms in industrial workers in Japan. Aliment Pharmacol Ther. 2001;15:805-11.

10. Kamada T, Haruma K, Hata J, Kusunoki H, Sasaki A, Ito M, Tanaka S, Yoshihara M. The long-tern effect on Helicobacter pylori eradication therapy on symptoms in dyspeptic patients with fundic atrophic gastritis. Aliment Pharmacol Ther. 2003;18:245-52. 
11. Iwakiri R, Tominaga K, Furuta K, Inamori M, Furuta T, Masuyama H, Kanke K, Nagahara A, Haruma K, Kinoshita Y, Higuchi K, Takahashi S, Kusano M, Iwakiri K, Kato M, Hongo M, Hiraishi H, Watanabe S, Miwa H, Naito Y, Fujimoto K, Arakawa T. Randomised clinical trial: rabeprazole improves symptoms in patients with functional dyspepsia in Japan. Aliment Pharmacol Ther. 2013;38:729-40.

12. Akutagawa K, Iwakiri R, Hara M, Fujimoto K, Fujiwara Y, Inamori M, Tanaka J, Shimatani T, Akiyama J, Ando T, Manabe N, Kinjo F, Deguchi R, Kusano M. Risk factors for low response to proton-pump inhibitor treatment in reflux esophagitis and non-erosive reflux disease evaluated by the frequency scale for the symptoms of gastroesophageal reflux disease. Esophagus. 2015;12:225-32.

13. Gwee KA, Teng L, Wong RK, Ho KY, Sutedja DS, Yeoh KG. The response of Asian patients with functional dyspepsia to eradication of Helicobacter pylori infection. Eur J Gastroenterol Hepatol. 2009;21:417-24.

14. Mazzoleni LE, Sander GB, Francesconi CF, Mazzoleni F, Uchoa DM, De Bona LR, Milbradt TC, Von Reisswitz PS, Berwanger O, Bressel M, Edelweiss MI, Marini SS, Molina CG, Folador L, Lunkes RP, Heck R, Birkhan OA, Spindler BM, Katz N, Colombo Bda S, Guerrieri PP, Renck LB, Grando E, Hocevar de Moura B, Dahmer FD, Rauber J, Prolla JC. Helicobacter pylori eradication in functional dyspepsia: HEROES trial. Arch Intern Med. 2011;171:1929-36.

15. Labenz J, Blum AL, Bayerdörffer E, Meining A, Stolte M, Börsch G. Curing Helicobacter pylori infection in patients with duodenal ulcer may provoke reflux esophagitis. Gastroenterology. 1997;112:1442-7.

16. Sugimoto M, Uotani T, Ichikawa H, Andoh A, Furuta T. Gastroesophageal reflux disease in time covering eradication for all patients infected with Helicobacter pylori in Japan. Digestion. 2016;93:24-31.

17. Kawai T, Moriyasu F, Tsuchida A. Key Issues associated with Helicobacter pylori eradication. Digestion. 2016;93:19-23.

18. Fujiwara Y, Arakawa T. Epidemiology and clinical characteristics of GERD in the Japanese population. J Gastroenterol. 2009;44:518-34.

19. Haruma K. Influence of Helicobacter pylori on gastrooesophageal reflux disease in Japan. Aliment Pharmacol Ther. 2004;20(Suppl 8):40-4.

20. Iijima K, Koike T, Shimosegawa T. Reflux esophagitis triggered after Helicobacter pylori eradication: a noteworthy demerit of eradication therapy among the Japanese? Front Microbiol. 2015;6:566.
21. Hirata K, Suzuki H, Matsuzaki J, Masaoka T, Saito Y, Nishizawa T, Iwasaki E, Fukuhara S, Okada S, Hibi T. Improvement of reflux symptom related quality of life after Helicobacter pylori eradication therapy. J Clin Biochem Nutr. 2013;52:172-8.

22. Kusano M, Hosaka H, Kawada A, Kuribayashi S, Shimoyama Y, Kawamura O, Moki F. Development and evaluation of a modified frequency scale for the symptoms of gastroesophageal reflux disease to distinguish functional dyspepsia from non-erosive reflux disease. J Gastroenterol Hepatol. 2012;27:1187-91.

23. Kusano M, Shimoyama Y, Sugimoto S, Kawamura O, Maeda M, Minashi K, Kuribayashi S, Higuchi T, Zai H, Ino K, Horikoshi T, Sugiyama T, Toki M, Ohwada T, Mori M. Development and evaluation of FSSG: frequency scale for symptoms of GERD. J Gastroenterol. 2004;39:888-91.

24. Takeshita E, Sakata Y, Hara M, Akutagawa K, Sakata N, Endo H, Ohyama T, Matsunaga K, Yoshioka T, Kawakubo H, Tanaka Y, Shirai S, Ito Y, Tsuruoka N, Iwakiri R, Kusano M, Fujimoto K. Higher frequency of reflux symptoms and acid-related dyspepsia in women than men regardless of endoscopic esophagitis: analysis of 3505 Japanese subjects undergoing medical health checkups. Digestion. 2016;93:266-71.

25. Lundell LR, Dent J, Bennett JR, Blum AL, Armstrong D, Galmiche JP, Johnson F, Hongo M, Richter JE, Spechler SJ, Tytgat GN, Wallin L, De Dombal FT, Margulies M. Endoscopic assessment of oesophagitis: clinical and functional correlates and further validation of the Los Angeles classification. Gut. 1999;45:172-80.

26. Palsson OS, Whitehead WE, van Tilburg MA, Chang L, Chey W, Crowell MD, Keefer L, Lembo AJ, Parkman HP, Rao SS, Sperber A, Spiegel B, Tack J, Vanner S, Walker LS, Whorwell P, Yang Y. Rome IV Diagnostic Questionnaires and Tables for Investigators and Clinicians. Gastroenterology. 2016;150:1481-91.

27. Iwakiri K, Kinoshita Y, Habu Y, Oshima T, Manabe N, Fujiwara Y, Nagahara A, Kawamura O, Iwakiri R, Ozawa S, Ashida K, Ohara S, Kashiwagi H, Adachi K, Higuchi K, Miwa H, Fujimoto K, Kusano M, Hoshihara Y, Kawano T, Haruma K, Hongo M, Sugano K, Watanabe M, Shimosegawa T. Evidence-based clinical practice guidelines for gastroesophageal reflux disease 2015 . J Gastroenterol. 2016;51:751-67.

28. Kawakubo H, Tanaka Y, Tsuruoka N, Hara M, Yamamoto K, Hidaka H, Sakata Y, Shimoda R, Iwakiri R, Kusano M, Fujimoto $\mathrm{K}$. Upper gastrointestinal symptoms are more frequent in female than male young healthy Japanese volunteers as evaluated by Questionnaire. J Neurogastroenterol Motil. 2016;22:248-53. 